\title{
Obesity, Blood Pressure, and Intraocular Pressure: A Cross-Sectional Study in Italian Children
}

\author{
Claudia Pileggi $i^{a}$ Rosa Papadopolia Caterina De Sarro ${ }^{a}$

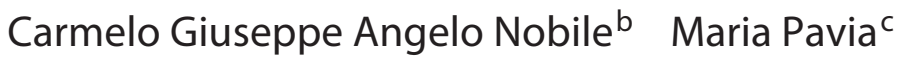 \\ aDepartment of Health Sciences, University "Magna Græcia” of Catanzaro, Catanzaro, Italy; ${ }^{\text {b Department of }}$ \\ Pharmacy, Health and Nutritional Sciences, University of Calabria, Cosenza, Italy; ${ }^{c}$ Department of Experimental \\ Medicine, University of Campania "Luigi Vanvitelli", Naples, Italy
}

\section{Keywords}

Blood pressure $\cdot$ Childhood obesity $\cdot$ Intraocular pressure $\cdot$

Overweight · Refractive error · Myopia

\begin{abstract}
Introduction: Several studies in the adult population have shown that obesity is an independent risk factor for elevated intraocular pressure (IOP), whereas data in the paediatric population are sparse and controversial. The purpose of the present study is to investigate the relationship between body mass index (BMI), blood pressure (BP), and IOP in healthy school children. Methods: The survey was conducted among a random sample of 8-year-old Italian students. Data were collected on their health status and behaviours related to obesity (physical activity, food and drinking habits, etc.). Physical examinations, conducted at school, included measurements of height, weight, BP, and IOP. Results: Five hundred and seventy-six subjects were recruited $(92.8 \%$ response rate); $42.4 \%$ were overweight or obese, $58.9 \%$ consumed inadequate daily servings of fruit and vegetables, and $87.5 \%$ were involved in sedentary activities. Elevated BP/hypertension (HTN) affected $3.6 \%$ and high IOP was revealed in $12.5 \%$ of the children. In the multivariate analysis, elevated $\mathrm{BP} / \mathrm{HTN}$ was the only significant determinant of ocular HTN (OR 5.36, 95\% Cl 1.95-14.73, $p=0.001$ ). Conclusions: Our re-
\end{abstract}

karger@karger.com www.karger.com/ofa

Karger!"

GOPEN ACCESS
(C) 2021 The Author(s)

Published by S. Karger AG, Basel

This article is licensed under the Creative Commons AttributionNonCommercial-NoDerivatives 4.0 International License (CC BY NC-ND) (http://www.karger.com/Services/OpenAccessLicense) Usage and distribution for commercial purposes as well as any distribution of modified material requires written permission. sults show that high IOP affects $12.5 \%$ of 8 -year-old school children and appears to be associated with high BP related to a high BMI.

(c) 2021 The Author(s)

Published by S. Karger AG, Basel

\section{Introduction}

It is well established that a high body mass index (BMI) has become a serious problem affecting about 30\% of school-aged children and adolescents [1-3]. The most alarming data refer to the global increase in the prevalence of overweight and obesity observed in the past 3 decades among children and adolescents aged 5-19 years [4].

A number of studies, mostly carried out in the adult population, have also shown that obesity is an independent risk factor for elevated intraocular pressure (IOP) [5, $6]$, whereas data in the paediatric population are sparse and controversial [7-11]. Elevated IOP might lead to glaucoma, characterized by an irreversible damage of the optic nerve with a gradual impairment of vision. If glaucoma is not treated, sight failure may proceed until the occurrence of complete sight loss. Analogously, elevated blood pressure $(\mathrm{BP})$ is considered as a potential risk factor for IOP in the adult population $[6,12,13]$ and it is well 
known that overweight and obesity are associated with elevated BP and hypertension (HTN) both in the adult population $[14,15]$ and among children and adolescents $[1,16,17]$.

Early detection of glaucomatous optic nerve damage allows the successful management of its development and elevated IOP is the only modifiable risk factor [18]. Therefore, a positive correlation between BMI, BP, and IOP could indicate obesity control in children also as a crucial strategy for glaucoma prevention. The purpose of the present study is to investigate the relationship between BMI, BP, and IOP in healthy school-aged children.

\section{Materials and Methods}

The study population consisted of a random sample of 8-yearold students attending 20 randomly selected primary schools among the 38 primary schools in the geographic area of Catanzaro (Italy) [19]. All parents of sampled children provided written informed consent and completed a questionnaire about their sociodemographic characteristics, anthropometric measures (height, weight), occurrence of chronic diseases, and smoking habits. They also provided data on the health status of their child (occurrence of diseases, eventual ophthalmic surgical interventions, steroid therapy). Before the examination, all children were interviewed about their health behaviours related to obesity, such as physical activity, diet, drinking, time spent watching TV and playing videogames or using computer. The frequency of sports activities and food habits were investigated according to the national nutritional surveillance system, coordinated by the National Institute of Health [20] and involved in the WHO European Childhood Obesity Surveillance Initiative (COSI). Countries participating in COSI explore trends in overweight and obesity among primary school children aged 6-9 years through biannual cross-sectional surveys in order to understand the progress of the epidemic in this population group, gain intercountry comparisons within the European region, and inform action to reverse the trend [3].

Examinations were conducted at school by trained and calibrated examiners. The height and weight of subjects with bare feet were recorded, waist circumference was measured at the umbilicus level over the T-shirt, and BMI was calculated by dividing the weight (in $\mathrm{kg}$ ) by the square of the height (in $\mathrm{m}$ ). Subjects were categorized as "at risk of overweight" if their BMI was between the 85th and 94th percentiles, and "obese" if their BMI was equal or over the 95th percentile, in accordance with the WHO [21] and the Italian reference data $[22,23]$. In particular, national BMI reference data, developed for subjects aged 2-20 years by the Italian Paediatrics Society of Diabetology and Endocrinology (SIEDP), were used [22,23]. These tables provide the percentiles of growth not only in relation to age and sex, but also to geographic area. Percentiles for Southern Italy were used.

$\mathrm{BP}$ was measured with the subject at rest and in a sitting position, using a mercury sphygmomanometer with an appropriately sized cuff. Three measurements were taken $5 \mathrm{~min}$ apart and the average value was used in the analysis for systolic BP (SBP) and diastolic BP (DBP). Normal BP was defined as SBP and DBP $<90$ th percentile for age, sex, and height; elevated $\mathrm{BP} / \mathrm{HTN}$ was defined as the average SBP or DBP $\geq 90$ th percentile [24-26].

An ophthalmologic examination was performed by an ophthalmologist. IOP was measured by an Icare portable tonometer [27]. Three measurements were obtained and an average value, expressed in $\mathrm{mm} \mathrm{Hg}$, was calculated. The results were categorized as "normal" or "high" IOP using the tables of the cross-sectional study conducted by Dusek et al. [8].

\section{Statistical Analysis}

The statistical analysis was conducted using the STATA software program, version 14.1 (StataCorp, College Station, TX, USA). Data are summarized using frequencies and percentages for categorical data and mean and SDs for continuous data.

Two models were developed using multivariate logistic regression analyses to identify the variables that affected the following outcomes: elevated BP/HTN $(0=$ no, $1=$ yes; Model 1$)$ and high IOP $(0=$ no, $1=$ yes; Model 2$)$. The following variables were included in the first model: BMI $(0=$ normal, $1=$ overweight or obese), steroid therapy $(0=$ no, $1=$ yes), physical activity (inadequate $=$ never, moderate $=1-3$ days $/$ week, adequate $\geq 4$ days $/$ week), consumption of snacks (adequate $\leq 1$ serving/week, inadequate $\geq 1$ servings/week), daily servings of fruit and vegetable (inadequate $<5$ daily servings, adequate $\geq 5$ daily servings), consumption of soft drinks/fruit juices (adequate $\leq 1$ serving/week, inadequate $>1$ servings/week), and having had breakfast on the day of examination $(0=$ no, $1=$ yes). In Model 2 the following variables were included: elevated BP/HTN $(0=$ no, $1=$ yes $)$, steroid therapy $(0=$ no, $1=$ yes $)$, time spent on homework $(0=\leq 2 \mathrm{~h} /$ day, $1=>2$ $\mathrm{h} /$ day), and refractive errors ( 5 categories: $0=$ none, $1=$ myopia, 2 = hyperopia, 3 = astigmatism, $4=$ more than 1 refractive error associated) included as a dummy variable, with no refractive errors being the reference category.

We did not include age and sex in the models because the tables of percentiles used to categorize children in relation to obesity, HTN, and high IOP were already corrected for age and sex. We followed the model-building procedure proposed by Hosmer and Lemeshow [28]. We first performed univariate analysis using the appropriate test statistic, and only the variables with a $p$ value $\leq 0.25$ were retained in the adjusted model. A backward elimination procedure was applied by setting $p=0.4$ as the significance level for dropping variables from the models. Adjusted odds ratios (OR) and 95\% CIs were calculated.

\section{Results}

A total of 576 subjects were recruited, with a response rate of $92.8 \%$. Among them, 551 children underwent a complete physical examination and their main characteristics are reported in Table 1. Students were evenly distributed among males and females; $42.4 \%$ were overweight or obese, with a higher prevalence in males (48.5\%) than females $(35.9 \%)$. Moreover, $52 \%$ of parents were overweight and $22 \%$ obese; $17.4 \%$ of children suffered from any chronic diseases, and, of these, $64 \%$ suffered from atopy. Nearly half (46.4\%) of the surveyed children 
had undergone steroid therapy in the previous year and, of these, only $9.2 \%$ had taken steroid drugs for more than 1 month.

Regarding lifestyle habits, $58.9 \%$ consumed inadequate daily servings of fruit and vegetables; just $7.8 \%$ and $13.1 \%$ did not exceed the daily consumption of snacks and of soft drinks/fruit juices, respectively; $89.1 \%$ had had breakfast on the day of the examination; $87.5 \%$ of the children spent more than $1 \mathrm{~h}$ watching TV or using a computer and playing videogames (data not shown). The mean SBP was $93.7 \mathrm{~mm} \mathrm{Hg}$, whereas the mean DBP was $46.4 \mathrm{~mm} \mathrm{Hg} ; 0.9 \%$ of subjects had elevated BP, and $2.7 \%$ HTN. Results of the univariate analysis indicated that elevated $\mathrm{BP} / \mathrm{HTN}$ in children was significantly associated with overweight and obesity ( $\chi^{2}=8.99,1 \mathrm{df}, p=0.003$ ), no consumption of breakfast on the day of examination $\left(\chi^{2}=8.32,1 \mathrm{df}, p=0.004\right)$, and with steroid therapy $\left(\chi^{2}=\right.$ 3.96, $1 \mathrm{df}, p=0.046$; Table 2).

Ophthalmologic examination results revealed that more than half of the surveyed children were affected by a refractive error. Hyperopia was the most common refractive error with a prevalence of $30 \%$. In $12.2 \%$ of children visual disorders were uncorrected because they were unknown to the parents (Table 1). Gender did not affect the prevalence of refractive errors $\left(\chi^{2}=13.55,11 \mathrm{df}, p=\right.$ 0.259). The mean IOP was equal to $16.5 \mathrm{~mm} \mathrm{Hg}$ (SD \pm 2.9 ), and high IOP in at least one eye was revealed in $12.5 \%$ of the children. No significant difference was found in the IOP between the 2 eyes $(t$ test $=-0.96,550 \mathrm{df}, p=$ $0.339)$, whereas a high IOP was significantly more likely in children with elevated BP/HTN $\left(\chi^{2}=15.72,1 \mathrm{df}, p<\right.$ 0.001 ; Table 2). The relationship between BMI and $\mathrm{BP}$ is displayed in Figure 1, and that between BP and IOP is shown in Figure 2. Results of the multivariate analysis indicated that elevated BP/HTN was significantly more frequent in overweight and obese children (OR 4.26, 95\% CI $1.35-13.42, p=0.013$ ) and in children who had not had breakfast on the day of examination (OR $0.30,95 \%$ CI $0.10-0.86, p=0.026$; Model 1 in Table 2), and elevated $\mathrm{BP} / \mathrm{HTN}$ was the only significant determinant of ocular HTN in the children (OR 5.36, 95\% CI 1.95-14.73, $p=$ 0.001; Model 2 in Table 2).

\section{Discussion}

According to current knowledge, childhood overweight and obesity are established risk factors for cardiovascular diseases and, in particular, of HTN. The important new insights added by our study, from a cross-
Table 1. Selected characteristics of the study population $(n=576)$

Age, years

$8.1 \pm 0.5$

HTN in parents

No

Yes

$434(79.5)$

$112(20.5)$

Ophthalmic diseases in parents

No

$272(49.8)$

Yes

$274(50.2)$

Parents' BMI

Low/normal weight

$135(26.1)$

Overweight

$269(51.9)$

Obese

$114(22)$

Chronic diseases in child ${ }^{\mathrm{a}}$

No

$464(82.6)$

Yes

$98(17.4)$

Ophthalmic diseases in child ${ }^{\mathrm{a}}$

No

$242(43.9)$

Yes, already known

Yes, not already known

$242(43.9)$

$67(12.2)$

$557(99.1)$

$5(0.9)$

Yes

$301(53.6)$

$261(46.4)$

Route of administration ${ }^{\mathrm{b}}$

Oral

$207(79.3)$

Local (cutaneous, conjunctival, aerosol)

88 (33.7)

Intravenous injection

$5(1.9)$

Intramuscolar injection

$1(0.4)$

$93.7 \pm 7.2$

$<90$ th percentile - normal BP

90-94th percentile - elevated BP

$542(97.5)$

$5(0.9)$

9 (1.6)

$\geq 95$ th percentile $-\mathrm{HTN}$

$46.4 \pm 9.7$

$540(97.1)$

$2(0.4)$

$<90$ th percentile - normal BP

90-94th percentile - elevated BP

$14(2.5)$

$\mathrm{BP}^{\mathrm{a}}$

$\geq 95$ th percentile $-\mathrm{HTN}$

$536(96.4)$

$5(0.9)$

$15(2.7)$

$18.7 \pm 3.7$

$320(57.6)$

$167(30)$

$69(12.4)$

85-94th percentile - overweight

$\geq 95$ th percentile - obese

$507(92)$

No

Yes

$44(8)$

Data are presented as the mean \pm SD or $n(\%)$.

a The numbers that do not add to 576 are due to missing data for the variable.

b Percentages do not add up to 100 due to multiple responses. 
Table 2. Results of the univariate and multivariate analysis

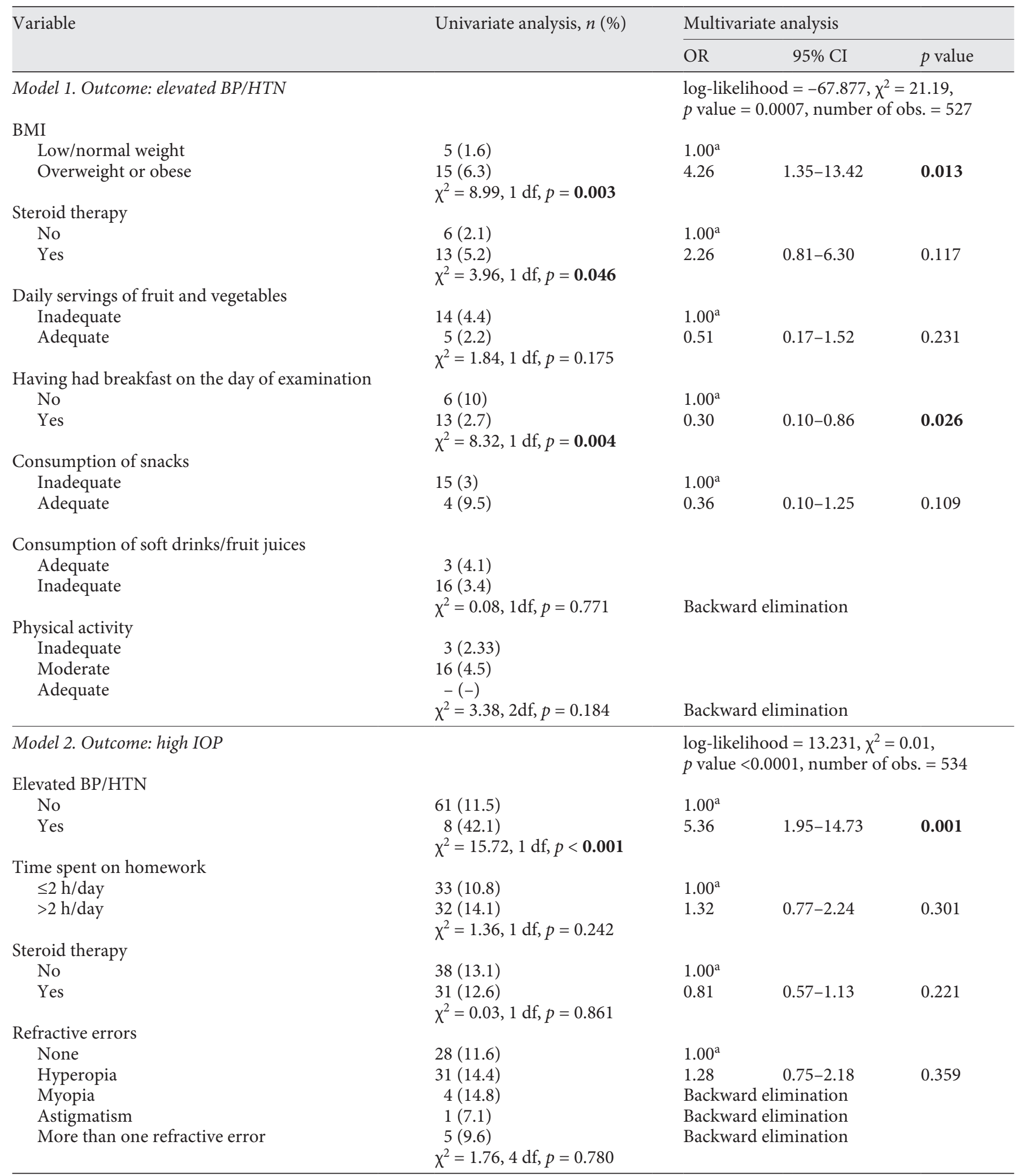

Bold $p$ values are statistically significant.

${ }^{a}$ Reference category. 
Fig. 1. Relationship between children's BMI and SBP (a) and DBP (b).

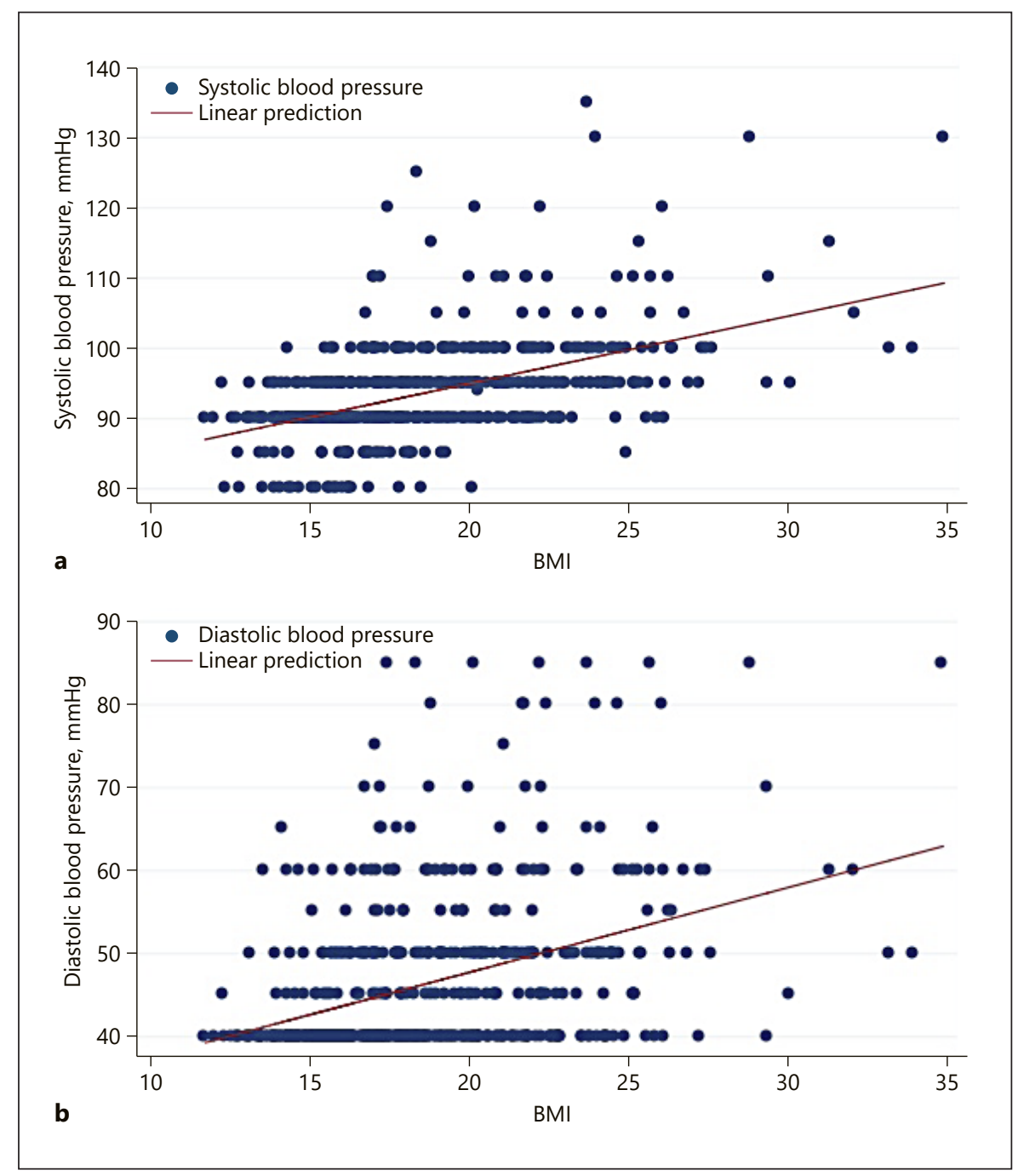

sectional point of view and after adjustment for many factors influencing body weight, is that elevated BP/ HTN related to high BMI in healthy children aged 8 years is consistently associated with high IOP, suggesting that the role of overweight and obesity is mediated through BP increase. Among the few studies that have investigated these associations in children, controversial results have been reported [7-11] and several pathophysiological structural and functional mechanisms linking elevated $\mathrm{BP} / \mathrm{HTN}$ with high IOP have been proposed. When BMI increases, levels of nitric oxide (NO), one of the principal endothelial-derived vascular relaxing factors, decline with a dysregulation of arteriolar diameters. Reduction of NO induces arteriolar vasoconstriction (Bayliss effect), which increases peripheral vascular resistance, thereby elevating BP. Additionally, microvascular endothelial function has been found to be

Child Obesity and High Intraocular Pressure inversely correlated with the percentage of body fat in pre-pubertal obese children [29], indicating the deleterious role of fat-induced inflammation on endothelial function that occurs early in life in obese children. In this context the results of a recent meta-analysis that investigated the association of obesity and elevated BP with retinal vessel diameters in children assume a particular interest [30]. Alterations of retinal vessel diameters are considered an effective indicator of cardiovascular risk [31] and the meta-analysis showed that obesity and elevated BP were consistently associated with narrower retinal arterioles. Therefore, it is possible to hypothesize that elevated BP in high IOP children induces a vasoconstrictive response resulting in narrower arteriolar diameters, thus suggesting the opportunity to also investigate the role of high IOP as an indicator of cardiovascular risk in obese children. 
Fig. 2. Relationship between IOP and SBP (a) and $\operatorname{DBP}(\mathbf{b})$.

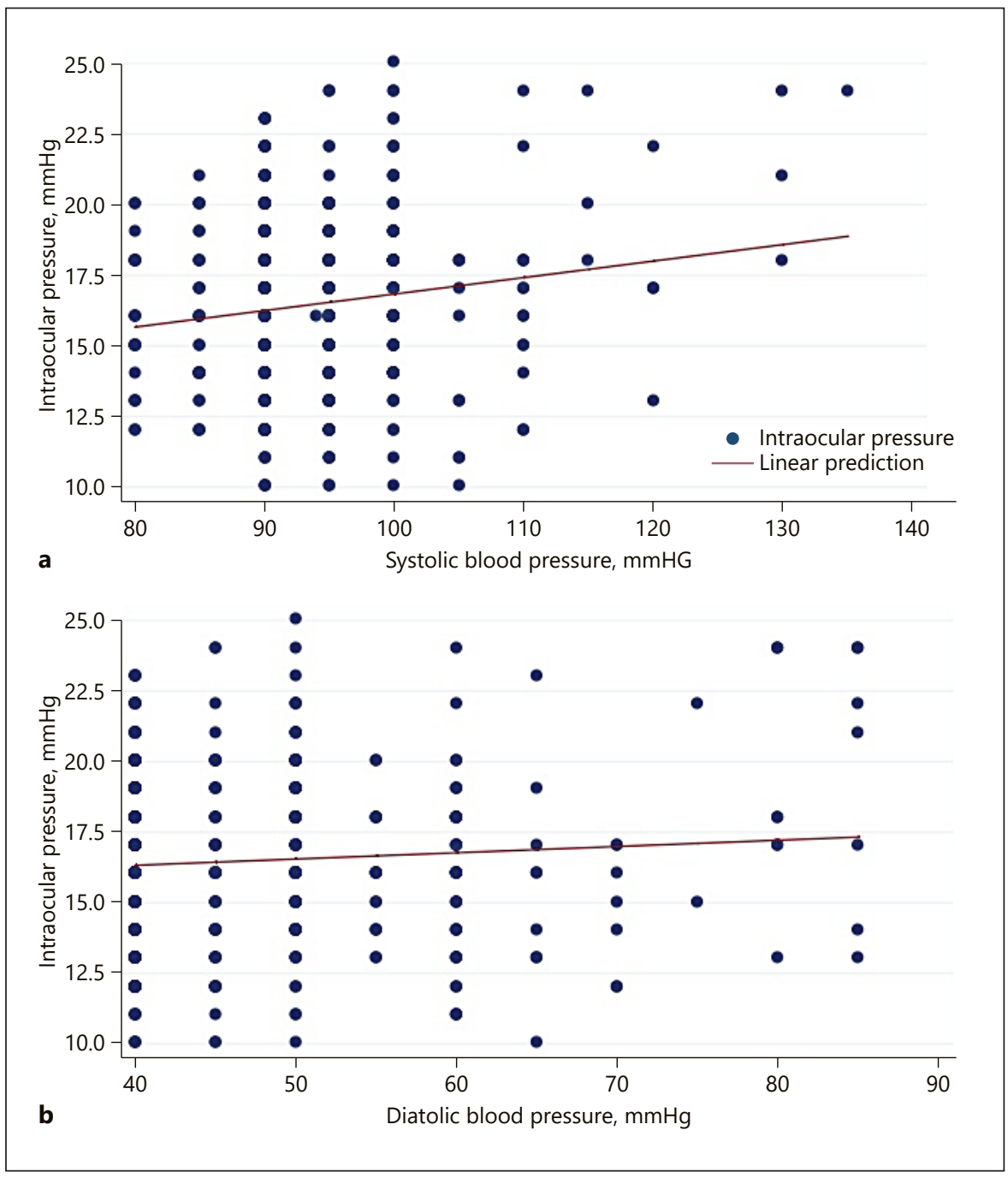

Another main finding of our study was the high prevalence $(12.5 \%)$ of IOP in the enrolled children, which is slightly higher than that reported in a previous investigation that evaluated the relationship between IOP and obesity in children (9.7\%) [7]. However, as mentioned above, few studies have investigated IOP in children, while research has been mainly focused on the adult population, albeit with contrasting findings [4-6]. Studies performed in children were designed and conducted with varying methodologies with regard to children's eye diseases, mainly conducted in patients with suspected pediatric glaucoma [32], or in hospitalized children who had undergone ocular surgery [33]. Among studies performed in the healthy population, the role of BP was erratically recognized. Indeed, Albuquerque et al. [9] and Koçak et al. [34] did not report any correlation between BMI and IOP; however, although Albuquerque et al. [9] measured
BP in children, they did not include it in the models performed to analyze the possible determinants of elevated IOP, and Koçak et al. [34] did not measure BP in the enrolled children. In line with our results, studies that considered $\mathrm{BP}$ as a determinant of IOP $[7,10]$ showed a positive association between BP and IOP.

Regarding the measurement of IOP, definitions of high IOP varied substantially across studies making it very difficult to compare the different results, reflecting our current poor understanding of what the most effective measurement scheme is. It is necessary, therefore, to take into account the age-specific value of each child, and the use of the percentile curves appeared to us to be the most appropriate tool to achieve this aim.

In our study we also reported that more than half of the surveyed children were affected by a refractive error. A broad range of studies [35-37] have investigated the 
association between high IOP and refractive errors, particularly myopia, reporting that the incidence of myopia in patients with IOP was significantly higher than that in the general population. Moreover, the hypothesis that the relationship between glaucoma and myopia could be mediated by BP has been suggested [37]. A prospective study indicated that a high IOP follows the onset of myopia and cannot cause myopia [38], which would imply that myopic eyes have a peculiar mechanism causing high IOP. On the other hand, IOP has been hypothesized to be implicated in the initiation and development of myopia. Elevated IOP could result in myopic axial elongation and promote myopia development. Several studies $[39,40]$ reported conflicting results that no difference of IOP was identified between myopes and emmetropes. Therefore, the role of IOP on axial length and refractive error development remains controversial.

\section{Limitations}

The potential limitations of the study should be mentioned. First, we did not assess the retinal vascular caliber that, over the last decades, has been used as a non-invasive diagnostic tool for the evaluation of cardiovascular health [31]; therefore, no eventual relative association with high $\mathrm{BP}$ and IOP could be evaluated. Second, we did not assess the central corneal thickness which could have influenced the IOP measurement. Moreover, previous studies highlighted the association between high IOP and higher BP both in statistical analysis models including central corneal thickness and in those that excluded it [27, 41, 42]. Third, the "gold standard" for IOP measurements is the Goldmann applanation tonometry (GAT), whereas in our study an Icare tonometry was used that, in a significant percentage of children, overestimates IOP by almost $2.3 \mathrm{~mm} \mathrm{Hg}$ compared with GAT [27]. However, the Icare tonometer has been demonstrated to be reproducible in healthy school children, easy to use, and comfortable for the patients $[43,44]$. Therefore, from a public health perspective, the Icare may be useful as a very sensitive screening tool for a first assessment of IOP, to be corroborated by clinical findings and subsequent confirmation by a different tonometry methodology. Finally, information on the metabolic health of the children (lipid profile, insulin resistance, glycemia, etc.) was not collected, though the association of obesity with HTN is also driven by metabolic changes. Our choice was, however, related to the need for the collection of a blood sample, and since the study was on healthy children, it would have been difficult to gain the consent for blood sampling, which is perceived as an invasive procedure. Further research on this topic should also include these characteristics to investigate in greater depth the role of the metabolic profile of children in the association of obesity with BP and IOP.

\section{Conclusion}

High IOP was found to affect $12.5 \%$ of 8 -year-old school children and appears to be associated with high BP related to high BMI. Therefore, considering that overweight and obesity, elevated $\mathrm{BP} / \mathrm{HTN}$, and unhealthy food habits were broadly spread in our population, our results strongly suggest that public health strategies, focused on promoting healthy lifestyles, should include regular IOP evaluation to identify ocular microvascular damage early in children with a high BMI, prior to the development of retinal damage. Further research is needed on the relationship between systemic and ocular biometric factors in the paediatric population, in which early intervention may be extraordinarily effective in the prevention of cardiovascular and ophthalmologic diseases later in life.

\section{Statement of Ethics}

Approval from the Institutional Ethics Committee ("Mater Domini" Hospital of Catanzaro, Italy) was obtained (No. 5, $13 / 3 / 2015)$. All parents of sampled children provided written informed consent.

\section{Conflict of Interest Statement}

The authors have no conflicts of interest to declare.

\section{Funding Sources}

There are no funding sources to declare.

\section{Author Contributions}

C.P. and M.P. conceived the study. C.P. contributed to data analysis and its interpretation, and contributed to the writing of the first draft of the article. R.P. contributed to the data interpretation and wrote the first draft of the article. C.D.S. and C.G.A.N. collected the data, and contributed to the writing of the first draft of the article. M.P. was responsible for the data analysis and interpretation, and wrote the final draft of the article. C.P. and M.P. critically reviewed the article for important intellectual content and are guarantors for the study. All authors read and approved the final version of the manuscript for submission. 


\section{References}

1 Pileggi C, Carbone V, Nobile CG, Pavia M. Blood pressure and related cardiovascular disease risk factors in 6-18 year-old students in Italy. J Paediatr Child Health. 2005 Jul; 41(7):347-52.

2 Pileggi C, Lotito F, Bianco A, Nobile CG, Pavia $M$. Relationship between chronic short sleep duration and childhood body mass index: a school-based cross-sectional study. PLoS One. 2013 Jun;8(6):e66680.

3 Wijnhoven TM, van Raaij JM, Spinelli A, Rito AI, Hovengen R, Kunesova M, et al. WHO European Childhood Obesity Surveillance Initiative 2008: weight, height and body mass index in 6-9-year-old children. Pediatr Obes. 2013 Apr;8(2):79-97.

4 Abarca-Gómez L, Abdeen ZA, Hamid ZA, Abu-Rmeileh NM, Acosta-Cazares B, Acuin C, et al.; NCD Risk Factor Collaboration (NCD-RisC). Worldwide trends in bodymass index, underweight, overweight, and obesity from 1975 to 2016: a pooled analysis of 2416 population-based measurement studies in 128.9 million children, adolescents, and adults. Lancet. 2017 Dec;390(10113):262742

5 Geloneck MM, Crowell EL, Wilson EB, Synder BE, Chuang AZ, Baker LA, et al. Correlation between intraocular pressure and body mass index in the seated and supine positions. J Glaucoma. 2015 Feb;24(2):130-4.

6 Kim HT, Kim JM, Kim JH, Lee JH, Lee MY, Lee JY, et al.; Korean Ophthalmological Society. Relationships between anthropometric measurements and intraocular pressure: the Korea National Health and Nutrition Examination Survey. Am J Ophthalmol. 2017 Jan 173:23-33.

7 Akinci A, Cetinkaya E, Aycan Z, Oner O. Relationship between intraocular pressure and obesity in children. J Glaucoma. 2007 OctNov;16(7):627-30.

8 Dusek WA, Pierscionek BK, McClelland JF. Age variations in intraocular pressure in a cohort of healthy Austrian school children. Eye. 2012 Jun;26(6):841-5.

9 Albuquerque LL, Gaete MI, Figueiroa JN, Alves JG. The correlation between body mass index and intraocular pressure in children. Arq Bras Oftalmol. 2013 Jan-Feb;76(1):10-2.

10 Yang DY, Guo K, Wang Y, Guo YY, Yang XR, Jing XX, et al. Intraocular pressure and associations in children. The Gobi Desert Children Eye Study. PLoS One. 2014 Oct 9(10):e109355.

11 Baran RT, Baran SO, Toraman NF, Filiz S, Demirbilek H. Evaluation of intraocular pressure and retinal nerve fiber layer, retinal ganglion cell, central macular thickness, and choroidal thickness using optical coherence tomography in obese children and healthy controls. Niger J Clin Pract. 2019 Apr;22(4): 539-45.

12 Park SS, Lee EH, Jargal G, Paek D, Cho SI. The distribution of intraocular pressure and its as- sociation with metabolic syndrome in a community. J Prev Med Public Health. 2010 Mar; 43(2):125-30

13 Ngo S, Harris A, Siesky BA, Schroeder A, Eckert G, Holland S. Blood pressure, ocular perfusion pressure, and body mass index in glaucoma patients. Eur J Ophthalmol. 2013 SepOct;23(5):664-9.

14 Alagiakrishnan K, Banach M, Ahmed A, Aronow WS. Complex relationship of obesity and obesity paradox in heart failure - higher risk of developing heart failure and better outcomes in established heart failure. Ann Med. 2016 Dec;48(8):603-13.

15 Jensen MD, Ryan DH, Apovian CM, Ard JD, Comuzzie AG, Donato KA, et al.; American College of Cardiology/American Heart Association Task Force on Practice Guidelines; Obesity Society. 2013 AHA/ACC/ TOS guideline for the management of overweight and obesity in adults: a report of the American College of Cardiology/American Heart Association Task Force on Practice Guidelines and The Obesity Society. J Am Coll Cardiol. 2014 Jul;63(25 Pt B):29853023.

16 Parker ED, Sinaiko AR, Kharbanda EO, Margolis KL, Daley MF, Trower NK, et al. Change in weight status and development of hypertension. Pediatrics. 2016 Mar 137(3):e20151662.

17 Perng W, Rifas-Shiman SL, Kramer MS, Haugaard LK, Oken E, Gillman MW, et al. Early weight gain, linear growth, and midchildhood blood pressure: a prospective study in project viva. Hypertension. 2016 Feb;67(2): 301-8.

18 Burr J, Vale L. Medical management of glaucoma. In: Shaarawy TM, Sherwood MB, Hitchings RH, Crowston JG, editors. Glaucoma. 2nd ed. Philadelphia: Saunders; 2015. p. 509-13, vol. 1. https://doi.org/10.1016/B9780-7020-5193-7.00047-9.

19 Istituto Nazionale di Statistica (ISTAT). Studenti e scuole dell'istruzione primaria e secondaria in Italia differenze strutturali tra scuole statali e paritarie (2017). Available at: https://www.istat.it/it/files/2017/04/Studenti-e-scuole.pdf.

20 Nardone P, Spinelli A, Buoncristiano M, Lauria L, Pierannunzio D, Galeone D. Istituto Superiore di Sanità. Surveillance system OKkio alla SALUTE: 2014 results. Notiziario Istituto Superiore di Sanità. Roma. 2016;3(29) Suppl. 1.

21 de Onis M, Onyango AW, Borghi E, Siyam A, Nishida C, Siekmann J. Development of a WHO growth reference for school-aged children and adolescents. Bull World Health Organ. 2007 Sep;85(9):660-7.

22 Cacciari E, Milani S, Balsamo A, Dammacco F, De Luca F, Chiarelli F, et al. Italian crosssectional growth charts for height, weight and BMI (6-20 y). Eur J Clin Nutr. 2002 Feb;56(2): 171-80.
23 Cacciari E, Milani S, Balsamo A, Spada E, Bona G, Cavallo L, et al. Italian cross-sectional growth charts for height, weight and BMI (2 to 20 yr). J Endocrinol Invest. 2006 Jul-Aug; 29(7):581-93

24 Menghetti E, Virdis R, Strambi M, Patriarca V, Riccioni MA, Fossali E, et al. Blood pressure in childhood and adolescence: the Italian normal standards. Study Group on Hypertension' of the Italian Society of Pediatrics'. J Hypertens. 1999 Oct;17(10):1363-72.

25 National High Blood Pressure Education Program Working Group on High Blood Pressure in Children and Adolescents. The fourth report on the diagnosis, evaluation, and treatment of high blood pressure in children and adolescents. Pediatrics. 2004 Aug; 114(2 Suppl 4th Report):555-76.

26 Flynn JT, Kaelber DC, Baker-Smith CM, Blowey D, Carroll AE, Daniels SR, et al. Clinical practice guideline for screening and management of high blood pressure in children and adolescents. Pediatrics. 2017 Sep; 140(3):e20171904.

27 Flemmons MS, Hsiao YC, Dzau J, Asrani S, Jones S, Freedman SF. Icare rebound tonometry in children with known and suspected glaucoma. J AAPOS. 2011 Apr;15(2):153-7.

28 Hosmer DW, Lemeshow S. Applied logistic regression. 2nd ed. New York: Wiley and Sons; 2000. https://doi.org/10.1002/0471722146.

29 Bhattacharjee R, Alotaibi WH, KheirandishGozal L, Capdevila OS, Gozal D. Endothelial dysfunction in obese non-hypertensive children without evidence of sleep disordered breathing. BMC Pediatr. 2010 Feb; 10(1):8.

30 Köchli S, Endes K, Infanger D, Zahner L, Hanssen H. Obesity, blood pressure, and retinal vessel: a meta-analysis. Pediatrics. 2018 Jun;141(6):e20174090.

31 Seidelmann SB, Claggett B, Bravo PE, Gupta A, Farhad H, Klein BE, et al. Retinal vessel calibers in predicting long-term cardiovascular outcomes: the Atherosclerosis Risk in Communities Study. Circulation. 2016 Nov; 134(18):1328-38.

32 Kooner K, Harrison M, Prasla Z, Albdour M, Adams-Huet B. Pediatric glaucoma suspects. Clin Ophthalmol. 2014 Jun;8:1139-45.

33 Youn DH, Yu YS, Park IW. Intraocular pressure and axial length in children. Korean J Ophthalmol. 1990 Jun;4(1):26-9.

34 Koçak N, Arslan N, Karti O, Tokgoz Y, Ozturk T, Gunenç U, et al. Evaluation of the intraocular pressure in obese adolescents. $\mathrm{Mi}$ nerva Pediatr. 2015 Oct;67(5):413-8.

35 Perkins ES, Phelps CD. Open angle glaucoma, ocular hypertension, low-tension glaucoma, and refraction. Arch Ophthalmol. 1982 Sep; 100(9):1464-7.

36 Quinn GE, Berlin JA, Young TL, Ziylan S, Stone RA. Association of intraocular pressure and myopia in children. Ophthalmology. 1995 Feb;102(2):180-5. 
37 Nomura H, Ando F, Niino N, Shimokata H, Miyake Y. The relationship between intraocular pressure and refractive error adjusting for age and central corneal thickness. Ophthalmic Physiol Opt. 2004 Jan;24(1):41-5.

38 Edwards $\mathrm{MH}$, Brown B. IOP in myopic children: the relationship between increases in IOP and the development of myopia. Ophthalmic Physiol Opt. 1996 May;16(3):243-6.
39 Lee AJ, Saw SM, Gazzard G, Cheng A, Tan DT. Intraocular pressure associations with refractive error and axial length in children. $\mathrm{Br}$ J Ophthalmol. 2004 Jan;88(1):5-7.

40 Manny RE, Deng L, Crossnoe C, Gwiazda J. IOP, myopic progression and axial length in a COMET subgroup. Optom Vis Sci. 2008 Feb; 85(2):97-105.

$41 \mathrm{Xu} \mathrm{L}$, Wang H, Wang Y, Jonas JB. Intraocular pressure correlated with arterial blood pressure: the beijing eye study. Am J Ophthalmol. 2007 Sep;144(3):461-2.
42 Jonas JB, Nangia V, Matin A, Sinha A, Kulkarni $\mathrm{M}$, Bhojwani K. Intraocular pressure and associated factors: the central India eye and medical study. J Glaucoma. 2011 Sep;20(7):405-9.

43 Sahin A, Basmak H, Niyaz L, Yildirim N. Reproducibility and tolerability of the ICare rebound tonometer in school children. J Glaucoma. 2007 Mar;16(2):185-8.

44 Pakrou N, Gray T, Mills R, Landers J, Craig J. Clinical comparison of the Icare tonometer and Goldmann applanation tonometry. J Glaucoma. 2008 Jan-Feb;17(1):43-7. 